\title{
Factors Influencing the User Acceptance of Alipay
}

\author{
Huijuan Guo ${ }^{1, a}$, Xin Huang ${ }^{2, b}$ and Paul Craig ${ }^{2, c}$ \\ ${ }^{1}$ Mid Sweden University, Sundsvall 510000, Sweden; \\ ${ }^{2}$ Xi'an Jiaotong-Liverpool University, Suzhou 215123, China.

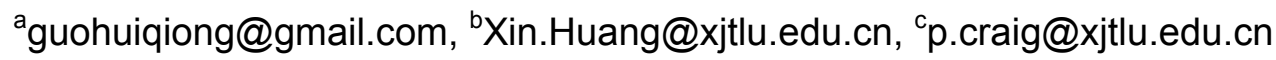

Keywords: Alipay, third-party online payment, user adoption, UTAUT model.

\begin{abstract}
This study looks at factors that influence user adoption of third-part-payment systems such as Alipay and PayPal. A research model and five hypotheses are proposed based on the Unified Theory of Acceptance and Use of Technology (UTAUT). These relate different factors to user adoption and form the basis of a survey which we present to a sample of 207 Chinese consumers. Our hypotheses are tested using a paired t-test with results revealing that, social influence, performance expectancy and facilitating conditions are the factors most likely to affect user adoption.
\end{abstract}

\section{Introduction}

With the massive growth in popularity of online shopping in the last twenty years, since the launch of Amazon.com in 1995, third-party online payment systems and users attitudes towards these systems have become increasingly important for commerce. Third party online payment also serves as a main payment solution used in the rapidly expanding Chinese market [4] where Alipay is the most popular payment platform. Alipay is a third-party online payment platform with no transaction fees. It was launched in 2004 by the Alibaba Group and has 300 million users controlling just under half of the Chinese online payment market [1]. Other significant players in the global online payment market are PayPal, Bitcoin and Google Wallet.

Despite the importance of online payment systems, there is limited research on the factors that affect user adoption. The aim of this study is to investigate user adoption of third-party online payment services so that future development of these systems can be better informed. As most of our sample group are Chinese, this study will focus on Aliplay as a case study to investigate online payment system adoption in general.

According to Aaker [2], all research methods can be divided into three categories; exploratory research, descriptive research, and causal research. This study falls under the categoty of causal research which emphasizes the study of a situation or problem in order to indicate the relationships between variables [3]. The purpose of this paper is to discover the factors that affect users' adoption of Alipay and there are several variables that may cause or determine the values of the dependent variable of user-adoption. The factors we look at are performance expectancy, social influence, facilitating conditions, effort expectancy and perceived risk. To test our hypotheses we collect empirical quantitative data through an online survey.

\section{Empirical data and results}

Aaker [2] indicated that the purpose of descriptive research is to provide an accurate introduction of certain aspects of the market environment. Descriptive research occupies a large proportion of marketing research. In order to get a more convenient understanding of the users' acceptance of Alipay from different participants, a descriptive analysis was applied for the demographic information collected in the survey. Frequency statistics for the background questions in the survey were calculated. These are shown in tables 1,2 and 3. 
Gender

Male

$45 \%$

Female

$55 \%$

Age

Under 20

$10 \%$

$20-29$

$53 \%$

30-39

$27 \%$

More than 39

$10 \%$

Occupation

Student

$48 \%$

Employee

$33 \%$

Self-employed

$4 \%$

Other

$15 \%$

Monthly income

Below 3000

$53 \%$

3000-4999

$12 \%$

$5000-8000$

$16 \%$

More than 8000

$19 \%$

Table 2 Online shopping habits (out of 207)

Shop online

$$
\begin{aligned}
& \text { Yes } \\
& \text { No }
\end{aligned}
$$

$96 \%$

$4 \%$

Time using Alipay

Less than 1 year

$23 \%$

1-2 years

$23 \%$

2-3 years

$22 \%$

More than 3 years

$32 \%$

Choice of payment

Alipay

$71 \%$

Online banking

$18 \%$

Pay on delivery

$5 \%$

other

$6 \%$ 
Table 3 Possible reasons for not using Alipay (out of 207)

$\begin{array}{cc}\text { Reasons for not using Alipay } & \\ \text { Internet is not convenient } & 6 \% \\ \text { I do not need Alipay } & 8 \% \\ \text { Security concerns } & 36 \% \\ \text { Cumbersome operation of Alipay } & 10 \% \\ \text { Other } & 40 \%\end{array}$

It can be seen from the table that we have slightly more female respondents than male respondents. There are $55 \%$ female respondents and $45 \%$ male respondants. Young people also made up a large proportion of the respondents. 53\% of the respondents are aged between 20 to 29 years old and $27 \%$ are between 30 to $39.10 \%$ are under 20 and $10 \%$ above $39.48 \%$ of the respondents are students and $33 \%$ employees. The rest are self-employed (4\%) and other (15\%).

Duration of Alipay usage was also measured in the study. As shown in the table, $32 \%$ of the respondents have been using Alipay for more than 3 years, which occupies the highest percentage. Respondents who have been using Alipay for 1-2 years and less than one year both account $23 \%$, while the percentage of respondents who have been using Alipay 2-3 years is $22 \%$.

From a monthly income respective, we can see from the table that $53 \%$ of the respondents' monthly income is below 3000 , as most of them are students. $19 \%$ of the respondents have a monthly income above 8000 , and $16 \%$ of the respondents are between 5000 and $8000.12 \%$ of the respondents are between 3000 and 4999 .

From the survey results, we find that $96 \%$ of the respondents do shopping online, only $4 \%$ of the respondents do not shop online. For those shopping online, $71 \%$ of them choose Alipay for payment, which takes up the largest part, while $18 \%$ of them use online banking and $5 \%$ of them pay on delivery. The other $6 \%$ select another payment method.

Ther reasons for respondents not using Alipay are also given. 36\% of users were concerned about security, $10 \%$ of them considered the operation of Aliplay to be cumbersome, $8 \%$ of them considered that they don't need Alipay, $6 \%$ of them thought that the internet itself was not convenient, and the remaining $40 \%$ had another reason for not using Alipay.

\section{Discussion and Conclusion}

The purpose of this study is to examine factors that affect the users' adoption of Alipay based on the UTAUT model. Muliple the factors were tested through a quantitative analysis using SPSS. According to the research question of what are the factors that affect the users' acceptance of Alipay?, the empirical data supports the following hypotheses;

Users with high performance expectancy will have a high intention to use Alipay.

Users' high social influence from others will have high intention to use Alipay.

Alipay's facilitating conditions positively affect the use behavior of Alipay.

Based on these results, performance expectancy can positively influence the users' intention to use Alipay. This indicates people believe that using Alipay enables them to finish payment quickly and that the software is usefull. Besides this, the factor "social influence" has the highest positive impact on the uses' behavioral intention. Users are strongly affected by thier peers when they are considering whether to use Alipay. Business managers could benefit from this conclusion when they plan effective marketing strategy in order to improve product value. Alipay can increase social influence to potential customers though carrying out social network marketing which can influence the effect of peer pressure. For example, Alipay could use social networking sites for promotion. 
Moreover, facilitating conditions can also positively impact users' intention to use Alipay, which means that the more comprehensive support system Alipay has, the more users are willing to use it. To respond to this third-pary payment system developers should develop assistance that is as complete as possible for users to be able to solve solve their online payment problems.

\section{References}

[1]. Alipay. (2015). [Online] Retrieved from : http://en.wikipedia.org/wiki/Alipay[Accessed:1 April 2015]

[2]. Aaker, D. A. (2001). Marketing research (7. ed.). New York: John Wiley \& Sons.

[3]. Saunders, M. (2012). Research methods for business students (6. ed.). Harlow; New York: Pearson.

[4]. Xie, J. S. \& Lin, R. Understanding the adoption of third-party online payment (2014) [Online] Available from: http://www.essays.se/essay/20a14d2696/ [Accessed: 27 March 2015] 